
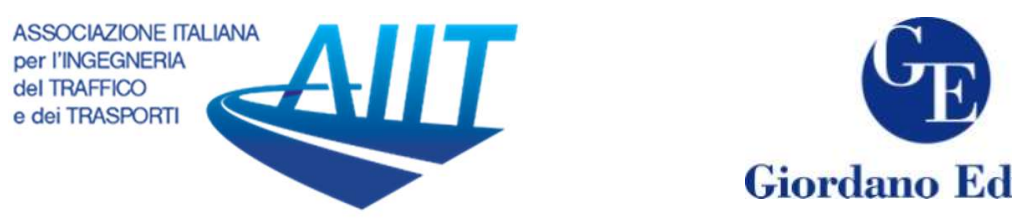

Giordano Editore

\title{
From urban planning techniques to 15-minute neighbourhoods. A theoretical framework and GIS- based analysis of pedestrian accessibility to public services
}

\author{
Barbara Caselli $^{1}$, Martina Carra ${ }^{2 *}$, Silvia Rossetti ${ }^{1}$, Michele Zazzi ${ }^{1}$ \\ ${ }^{1}$ University of Parma, Department of Engineering and Architecture, Parma, Italy \\ ${ }^{2}$ University of Brescia, Department of Civil, Environmental, Architectural Engineering and Mathematics, \\ Brescia, Italy
}

\begin{abstract}
The enthusiasm with which several metropolises have promoted and embraced the idea of the '15-minute city' may now provide a useful opportunity to reflect once again on the well-known relationship between urban planning and mobility planning. Urban policies and plans are recently rediscovering a new focus on the proximity dimension and active mobility, progressively excluding the obsolete car-centric model. In this perspective, the paper aims at assessing 15-minute neighbourhoods through a GIS-based model to evaluate pedestrian accessibility to urban services and spaces. The implemented methodology integrates the assessment of walking distances and the mapping of the resident population distribution. The method is then applied to measure the current performance of an existing neighbourhood in Parma, assessing accessibility based on home-facility travel times and the resident population within reach. A reflection is proposed on what has been learned and on the possible contribution that the method can bring to urban monitoring and planning.
\end{abstract}

Keywords: 15-minute neighbourhood; Pedestrian accessibility; GIS; Isochrones.

\section{Introduction}

The construction of the physical city has traditionally been based on the need to solve two basic problems of community life: firstly, finding areas (covered or uncovered) for the various social functions (residential, productive, commercial, technological, service, green, etc.); secondly, equipping the space to connect the activities carried out in those functional areas. Over time, sophisticated techniques have been developed to make movement within an ever-expanding urban space easy and efficient, with an everincreasing number of citizens moving towards an equally large number of potential destinations. And this with the pressing need to shorten travel times as much as possible.

\footnotetext{
*Corresponding author: Martina Carra (martina.carra@unibs.it)
} 
In recent years, shared programs (e.g., Urban Agenda 2030, EU Guidelines) have shown that one of the most critical challenges contemporary cities must face is enhancing proximity. Indeed, there is a heavy relation between the objective of improving sustainability and proximity.

These challenges and needs of the built environment have become even more evident in the context of the Covid-19 pandemic. Indeed, several countries (e.g. Italy, France, Germany, Spain, and United Kingdom) have adopted restrictive measures to contain infections focused on movement regulation to keep social distancing. The regulation brought about three major changes. Firstly, it limited the movements only to "daily needs" services; secondly, it limited the maximum distance allowed for free time activities (e.g., walking in green areas, doing individual sports, etc.); Thirdly, it significantly reduced the public transport capacity. These three major changes furtherly aggravated well-known issues that cities have been facing for a long time, such as the organisation of urban times and spaces (Zecca et al., 2020), the lack of a widespread provision of public services, insufficient public transport, the unsustainability of certain working models, the increase in motorised mobility, environmental impacts, and social inequalities.

Although, interestingly, the radical spatial confinement introduced by the health emergency resulting from the pandemic has also revived a concept of proximity linked to individual lifestyles, according to 'slow' movements in a much more limited urban environment. This vision takes concrete form in the so-called 15-minute city (Moreno et al., 2021), focusing on the 'walkable distance' from one's home to nearby urban services and spaces. Recently, pilot projects have been proposed in important European cities such as Paris and Milan.

As it often happens, the initial enthusiasm over the 15-minute city concept can be followed by a reflection on the possible consequences of a 'reductive' approach to the planning and management of cities based solely on the 15-minute concept. In other words, on the opportunity to accept as plausible the hypothesis that, by solving the problems of accessibility through a reorganisation of urban services networks and the slow mobility networks, it is possible to build an overall scenario of innovation for the transformation of the contemporary city. Nevertheless, many questions remain: have suitable methodological assumptions been established to detect the conditions in place to operate on the existing city? How is it possible to measure the 15 minutes city? Can such assessments become an opportunity for a general improvement of the urban layout organisation?

This paper aims to contribute both theory and practice. Firstly, it investigates the evolution of the proximity concept that led to the 15-minute city concept. Secondly, it introduces a GIS-based method for evaluating pedestrian accessibility to public services at the neighbourhood scale. The proposed GIS-based method is an advancement of ongoing research (Zazzi et al., 2018; Rossetti et al., 2020) and represents an attempt to integrate qualitative and quantitative analysis of pedestrian accessibility to neighbourhood services with the detailed mapping of resident population. The method is applied to the case study of a neighbourhood in Parma.

The paper is organised as follows. Section 2 critically analyses the theme of urban accessibility from the neighbourhood unit model to the 15-minute city. Section 3 explains the GIS-based method to evaluate pedestrian accessibility to neighbourhood services and maps the population distribution/composition within reach. Section 4 presents the results of the method applied to the case study of the Cittadella district in Parma. Finally, Section 
5 analyses the pros and cons of the method and provides a possible research agenda to the theme of 15-minute cities.

\section{Proximity issues in the urban planning techniques}

\subsection{From the neighbourhood unit model to the 15-minute city}

The benefits induced by the proximity dimension, revived by the 15-minute city by Carlos Moreno, are many and have been generally shared for a long time in the academic field (e.g., Handy and Clifton, 2001; Bertolini et al., 2005): the reduction of environmental impacts, the promotion of sustainability, the increase of sociality and inclusiveness (especially for disadvantaged groups), the improvement of psychophysical wellness (Weng et al., 2019; De Vos, 2020).

Anne Hidalgo, mayor of Paris, included in her January 2020 re-election campaign programme the idea of Paris as a Ville $d u$ quart d'heure. The immediate success of this initiative contributed to her re-election as mayor and inspired policies and strategies to deal with the health emergency that the city faced in the following months. In this regard, we can also certainly mention the adaptation strategy developed by the city of Milan in 2020 and the related action projects and tools for cycling and walking, Strade Aperte (Municipality of Milan, 2020), in which specific reference is made to the district 'with everything in 15 minutes'. The implementation is also based on a network of districts with a pedestrian vocation previously identified by the urban plan 2030 (Municipality of Milan, 2019).

With specific reference to the need to introduce the concept of the 15-minute city, it is, therefore, necessary to reiterate that it deals with themes and principles that are not new in the literature but belong to some fundamental references of the urban planning techniques (Pozoukidou and Chatziyiannaki, 2021). Several previous studies can be divided into two main research themes: the concept of neighbourhood unit and accessibility.

The concept of neighbourhood unit has been theorised by Clarence Perry (1929) as a distinct entity (a core) part of a larger whole (the city). Perry (1929) proposed a spatial scheme for the unit defining design standards that included dimensional factors (e.g., population density, $10 \%$ of recreation and park space) and functional amenities (e.g., shops, schools, green areas, community centre). In recent times, Perry's scheme is strongly taken up by the studies of the Urban Task Force (1999), coordinated by Lord Rogers, as well as the New Urbanism movement (Calthorpe, 1993; Katz, 1993). The residential units are organically connected to the functional cores to minimise walking distances; moreover, the central area is characterised by mixed uses and varying densities within a few minutes walking distance. The 15-minute cities model can be considered complementary also to the TOD's accessibility model or assimilable to the recent Slow cities concept (Mezoued et al., 2021).

Even in Italy, these studies have a long history. One of the most relevant is the Organic urbanism concept by Vincenzo Columbo (1966). According to Columbo, the neighbourhood was the cell of the city, comprising the home and basic services, such as basic shops, nursery schools, and extensive public parks, all of which could be accessed on foot in five minutes. This study was later taken up and updated by the 'Friendly City Study Centre for Safety in Mobility' at the University of Brescia, which, relying on the 
results of the international conference 'Living and Walking in Cities', combines the urban mobility issues with those of urban planning and quality of life in urban areas (Busi, 2011; Tira et al., 2020).

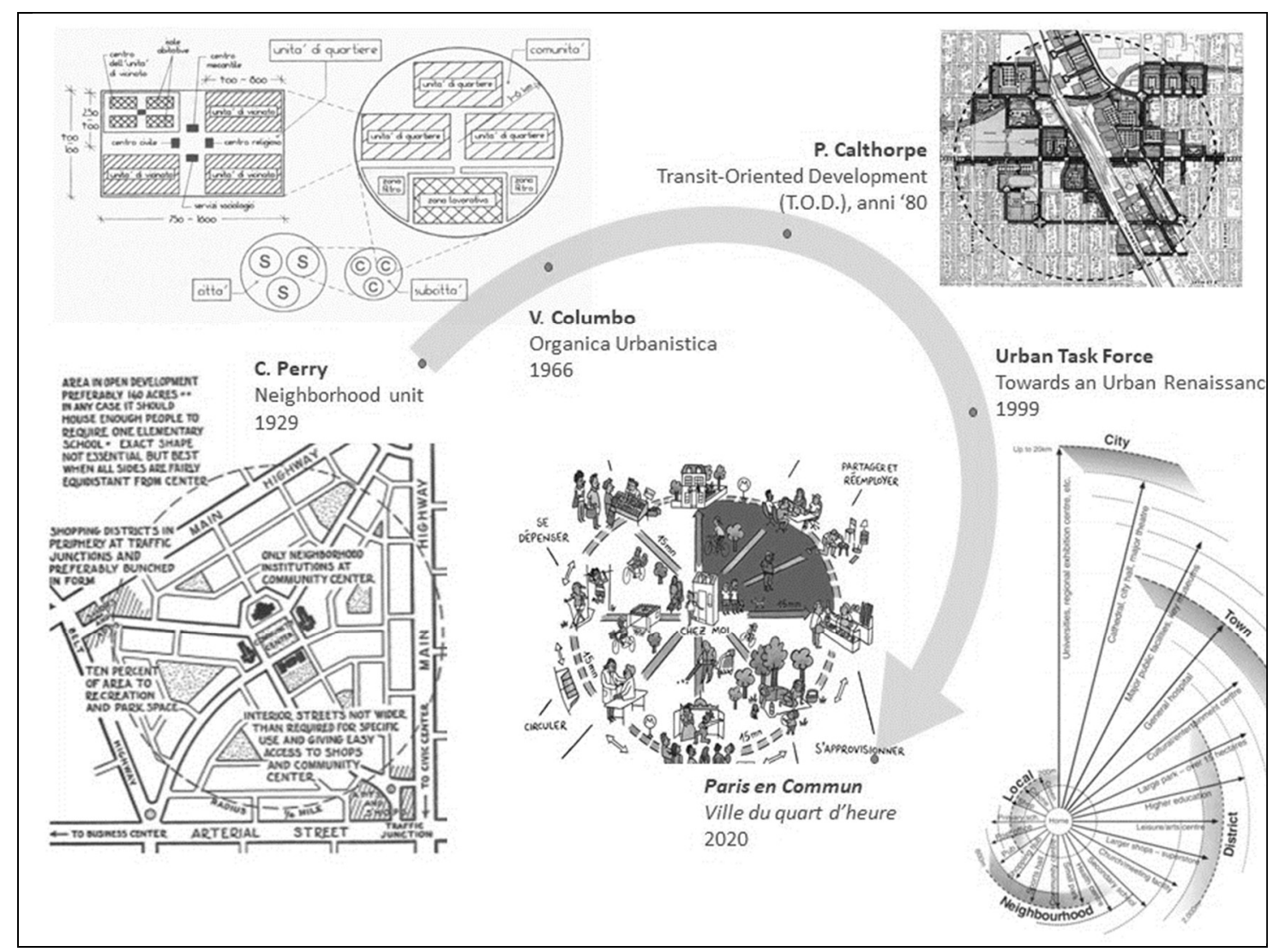

Figure 1 - From the neighbourhood unit to the 15-minute city. Some of the disciplinary references.

Therefore, the issue of proximity is an old concept that has unfortunately acquired a new meaning due to the Covid-19 pandemic. Indeed, Carlos Moreno's 15-minute concept is indebted to the long-term debate on neighbourhood accessibility (Moreno et al., 2021; Handy and Clifton, 2001). Additionally, Moreno relates the concept of chrono-urbanism to a resilient, sustainable, and inclusive city "where proximity is vibrant and where social intensity is real". Thus, applying objectives of Urban Agenda 2030 and following the recommendation of C40 Cities (2020) to bring activities within the neighbourhoods, decentralising core services with flexible uses, developing a social and functional mix, engaging people in urban planning processes, improving walking and cycling infrastructures.

\subsection{Proximity and urban accessibility analysis}

Considering the driving force of the 'slogan' of the 15-minute city and the long-term reflections that allow a better disciplinary contextualisation, it seems appropriate to question the role of proximity in the technical contents of contemporary urban practices. 
On these aspects, a transfer of solutions and competencies from research activities to operational practices still seems necessary. The research on how to create pedestrianfriendly urban areas by improving and properly designing pedestrian infrastructures is consolidated and can have insights on all walking specific aspects, such as practicability, road safety and attractiveness of the pedestrian network (Forsyth, 2015).

From a theoretical and methodological point of view, both the characteristics of the networks and infrastructures for mobility and the criteria for the location of potential destinations that contribute to the realisation of the 15-minute city are widely discussed in studies on urban accessibility (Balletto et al., 2021; Da Silva et al., 2020; Rossetti and Zazzi, 2020; Tiboni et al., 2021). In particular, it is possible to consider physical proximity, understood as the proximity and closeness of people, activities and urban functions, as one of the possible strategies, if not the main one, with which urban accessibility, understood as the possibility of accessing the various desired destinations, variously distributed in the urban space, can be developed and improved.

From the application point of view, one of the first questions to be addressed concerns the possibility of measuring how well an urban area is structured to support the 15-minute model and assessing whether a neighbourhood is accessible in 15 minutes based on population distribution, the location of desired activities and the quality of pedestrian networks. There is a need for a better definition of the technical tools to deal with the integrated study of the physical and morphological characteristics of urban areas, the design of networks and infrastructures for soft mobility, and the offer of activities and services.

In this case, the research has built up solid evaluation techniques based on the analysis of functions, correct distribution and services provision, with different levels of accessibility. Other in-depth studies concern the principles of form and location that favours the right measure of functional mix and compactness as well as decentralisation and capillarity of neighbourhood services (Bibri et al., 2020; Cervero and Kockelman, 1997).

Similarly, the issue of analysing pedestrian characteristics of a neighbourhood or, more generally, of an urban area can refer to established studies that allow sophisticated analysis of walkability levels. Several walkability indices and measures are available in the literature, generally based on urban form characteristics such as density, land use mix and road connectivity (Conticelli et al., 2018; Garau et al., 2020). These analyses are mainly based on assessments made through GIS applications and geoprocessing tools that process different data sets, allowing the evaluation of spatial conditions of walkability along the pedestrian network (Rossetti et al., 2020; Carpentieri et al., 2019; Gargiulo et al., 2021; Mezoued et al., 2021). The main applications consider various walkability indices, such as connectivity, safety, comfort, accessibility, and convenience, which make it clear that walkability can be better described using a composite set of indicators (Caselli et al., 2021; Ignaccolo et al., 2020; Campisi et al., 2020; Tiboni \& Ignaccolo, 2020; Weng et al., 2019).

Despite the different techniques and indicators adopted, all the considerations over the 15-minute city introduce a fundamental temporal dimension. The time factor is frequently assessed using a buffer analysis (Da Silva, 2020), isochrone maps (Rossetti et al., 2020) or closest facility analysis (Zazzi et al., 2018). However, these types of analysis still seem in the background in the planning practice.

Within this framework, the paper presents a comprehensive GIS-based methodology to measure the current performances of an existing neighbourhood of a medium-sized city 
from the 15-minute city perspective, which can become a support tool for city policies. Through this analytical technique, based primarily on the acquisition of information layers related to the population distribution, the detailed mapping of the pedestrian network and the location of desired activities and public services, it is possible to formulate measures of accessibility and, consequently, evaluate, albeit theoretically, the degree of satisfaction of the settled population potential needs.

\section{A GIS-based methodology for the 15-minute neighbourhood}

\subsection{Evaluate pedestrian accessibility to neighbourhood services}

In the proposed study, the 15-minute city theme is addressed with an analytical model designed and developed using GIS to assess existing conditions of accessibility to neighbourhood services for all the resident social groups. The methodology is applied to a peripheral area where pedestrian accessibility to proximity services is not generally preferred and therefore should be encouraged.

The GIS-based model has been implemented by improving and integrating a Territorial Information System (TIS) previously adopted to assess pedestrian accessibility to neighbourhood services. The original TIS, managed with the ArcGIS software, is based on a vector data structure and incorporates various layers - pedestrian paths, public services (schools, green areas), traffic areas, buildings, house numbers - implemented, making use of open data and in-field inspections.

In particular, the pedestrian paths feature class, which is the TIS core dataset, has been generated as a link-node graph by detecting the actual pedestrian network. In the graph, all walking routes available on the public space have been mapped: pavements, crossing paths and walkways, especially those allowing users to walk across green areas. The network also comprises virtual pavements and virtual crossing paths, assuming that users, in the absence of a dedicated path or a marked crossing path, might choose to walk along road margins or cross in the proximity of road intersections.

The mapped links have then been associated with qualitative and quantitative attributes collected through a careful urban survey campaign. The data collected makes it possible to assess whether the routes can meet the needs of all possible users. Factors that can influence the quality of the walking experience have also been included, such as dimensional and morphological features, paving materials, safety measures, presence of attractive uses and functions and, above all, the time factor. In fact, for each link of the pedestrian network, a "cost" value, i.e., the ratio between the link length and pedestrian walking speed, estimated at $3 \mathrm{~km} / \mathrm{h}$, has been calculated. The National Research Council (2000) recommends a walking speed value of about $4-5 \mathrm{~km} / \mathrm{h}$. However, in urban areas with large numbers of older pedestrians (e.g., in Italian cities), it recommends a walking speed value of $1.0 \mathrm{~m} / \mathrm{s}$ (about $3.5 \mathrm{~km} / \mathrm{h}$ ). Indeed, choosing a lower value allows a more inclusive approach to all road users, especially the most vulnerable ones.

The computing of the cost, expressed in minutes, also considers a "delay factor" (DF) at pedestrian crossings. This is slightly different depending on whether crossings are signalised (with traffic light) or unsignalised (see table 1). In the absence of a traffic control device, the average pedestrian waiting time at intersections has been estimated between 20 and 30 seconds, while in the presence of a traffic light, the DF is estimated between 40 and 60 seconds, equal to the average signal cycle length (NACTO, 2016; 
FHWA, 2008; NCHRP, 2015; National Research Council, 2000). A wide literature reports detailed modelling studies on pedestrian crossing behaviour and pedestrian waiting times at intersections. However, in this contribution, simplified average values have been collected only from manuals, being sufficiently functional to evaluate the average travel times along pedestrian paths. Planning the enhancement of pedestrian accessibility to public services brings in issues of time and distance besides quality. That is why the "cost" value is a crucial attribute in the analysis.

Table 1: "Cost" value computing.

\begin{tabular}{|c|c|c|}
\hline Pedestrian path typology & & COST [minutes] \\
\hline Pavements, Virtual pavements Walkways & & Length $[\mathrm{km}] / 3[\mathrm{~km} / \mathrm{h}] * 60$ \\
\hline \multirow[t]{3}{*}{ Crossing Paths } & & $\begin{array}{l}\text { Length }[\mathrm{km}] / 3[\mathrm{~km} / \mathrm{h}] * 60+\mathrm{DF}[\text { minutes }] \\
\text { where: }\end{array}$ \\
\hline & $\rightarrow$ & Unsignalised pedestrian crossing \\
\hline & $\rightarrow$ & Signalised pedestrian crossing \\
\hline
\end{tabular}

Source: Elaboration from NACTO, 2016; FHWA, 2008; NCHRP, 2015; National Research Council, 2000.

The model has been first applied to the northern portion of the Cittadella district, a predominantly residential area of about 138 hectares in the first outskirts of the mediumsized city of Parma.

Data processing with ArcGIS Network Analyst tools produced different simulations, mapping walking times and the quality of pedestrian accessibility to proximity services. In particular, the model pilot application produced, firstly, a pedestrian isochrone map considering a selection of public schools (middle schools) and walking distances of 3, 5 and 10 minutes; secondly, the closest facility map, considering the same public facilities and mapping all the fastest home-service routes starting from each house number, thirdly, the evaluation of the quality of the fastest routes, identifying possible criticalities.

The improved model also maps the detailed distribution of the resident population and identifies the main neighbourhood cores, i.e. urban nodes well served by necessities shops and services, such as supermarkets, grocery stores, bars, drugstores, and banks. Specifically, the improved study application focuses on preschool facilities (kindergartens) and these newly mapped neighbourhood cores (Figure 1). 


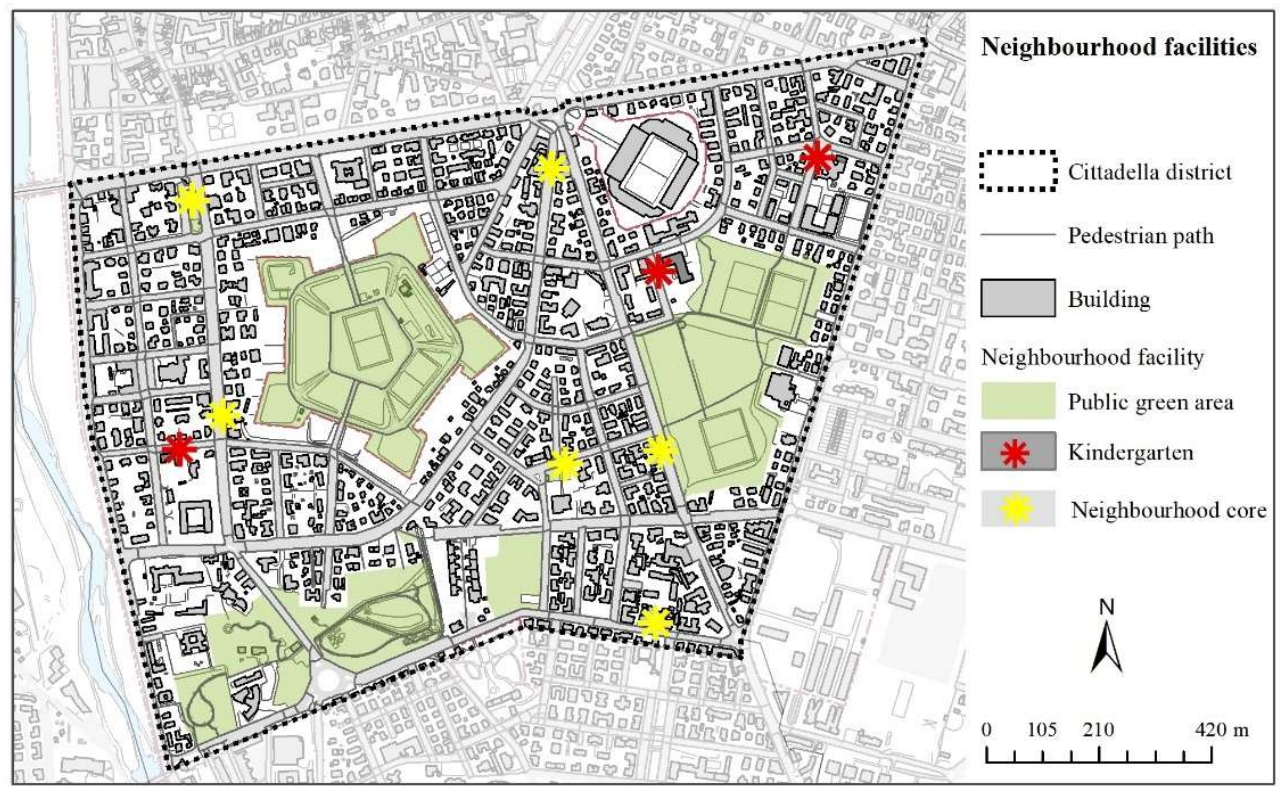

Figure 2: Analysed neighbourhood facilities: kindergartens and neighbourhood cores. Source: Authors.

\subsection{Integrating the methodology by mapping the resident population distribution and composition}

To assess accessibility within the 15-minute neighbourhood, it is essential to define the sources, the origins of the mobility need, which for a neighbourhood service can be represented by the population distribution. The official census provides population data aggregated per census tracts, which within cities often coincide with urban blocks or even with entire neighbourhoods. Those data are very useful to assess accessibility at a city scale or for wider/regional areas. However, they may be not detailed enough to describe accessibility to neighbourhoods' services and facilities. Therefore, a detailed spatial distribution map of the population can be defined to describe exactly how inhabitants are distributed within the neighbourhood. For the Cittadella case study, inhabitants were located through a georeferencing process of the demographic registry of the Municipality of Parma, as described in figure 3.

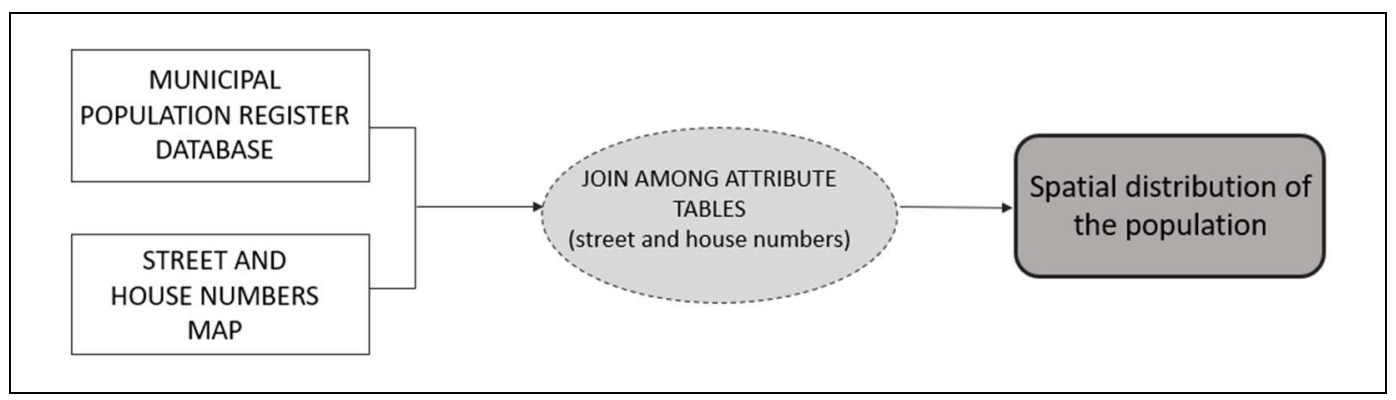

Figure 3: Procedure to map the population distribution, starting from the municipal register database and the shape file of civic numbers. 
Source: Authors.

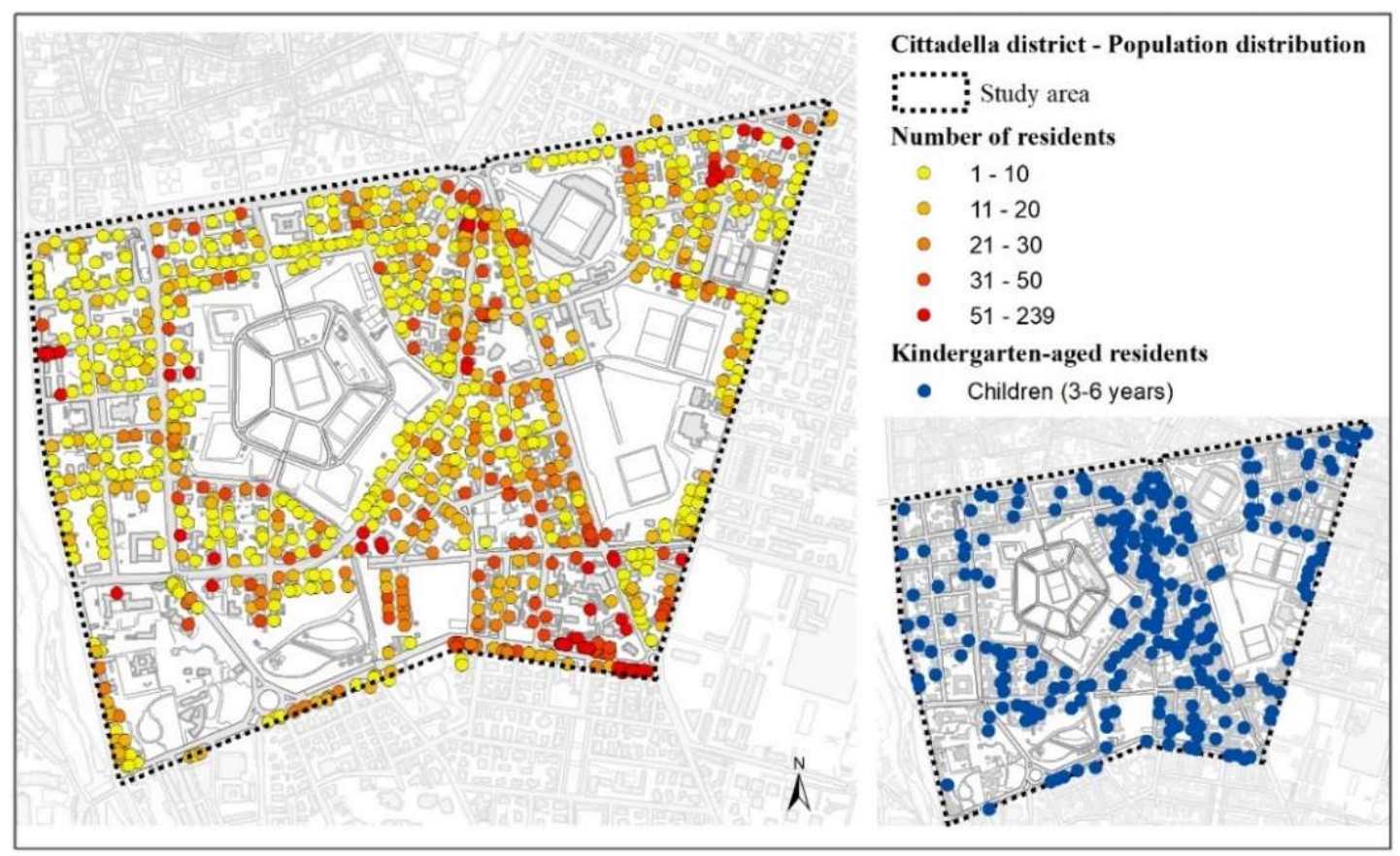

Figure 4: Population distribution in Cittadella District: examples of elaborations based on the georeferenced inhabitants.

Source: Authors.

The result of this georeferencing process can be mapped through a set of punctual elements (Figure 4). In correspondence with each house number, many points correspond to the inhabitants associated with that house number. In the attribute table, each point is associated with all the information available in the registry for each inhabitant (e.g., gender, age, date of birth, etc.).

\section{Assessment of a 15-minute neighbourhood: the Cittadella district in Parma}

\subsection{Isochrones map for assessing accessibility based on walking times}

The accessibility assessment in the case study of the Cittadella district has been carried out processing data to determine the catchment areas of selected collective facilities in the neighbourhood through the Service Area analysis, an ArcGIS Network Analyst tool. Two isochrone maps have then been produced, identifying kindergartens and neighbourhood cores as the main locations, computing the "cost" value per each link in the pedestrian network, and choosing three benchmark values for travel times: 5, 10 and 15 minutes. Therefore, each network-based Service Area includes all pedestrian links that can be reached within a 5, 10 and 15-minute walk from chosen facilities, also considering probable slowdowns caused by street crossing. 


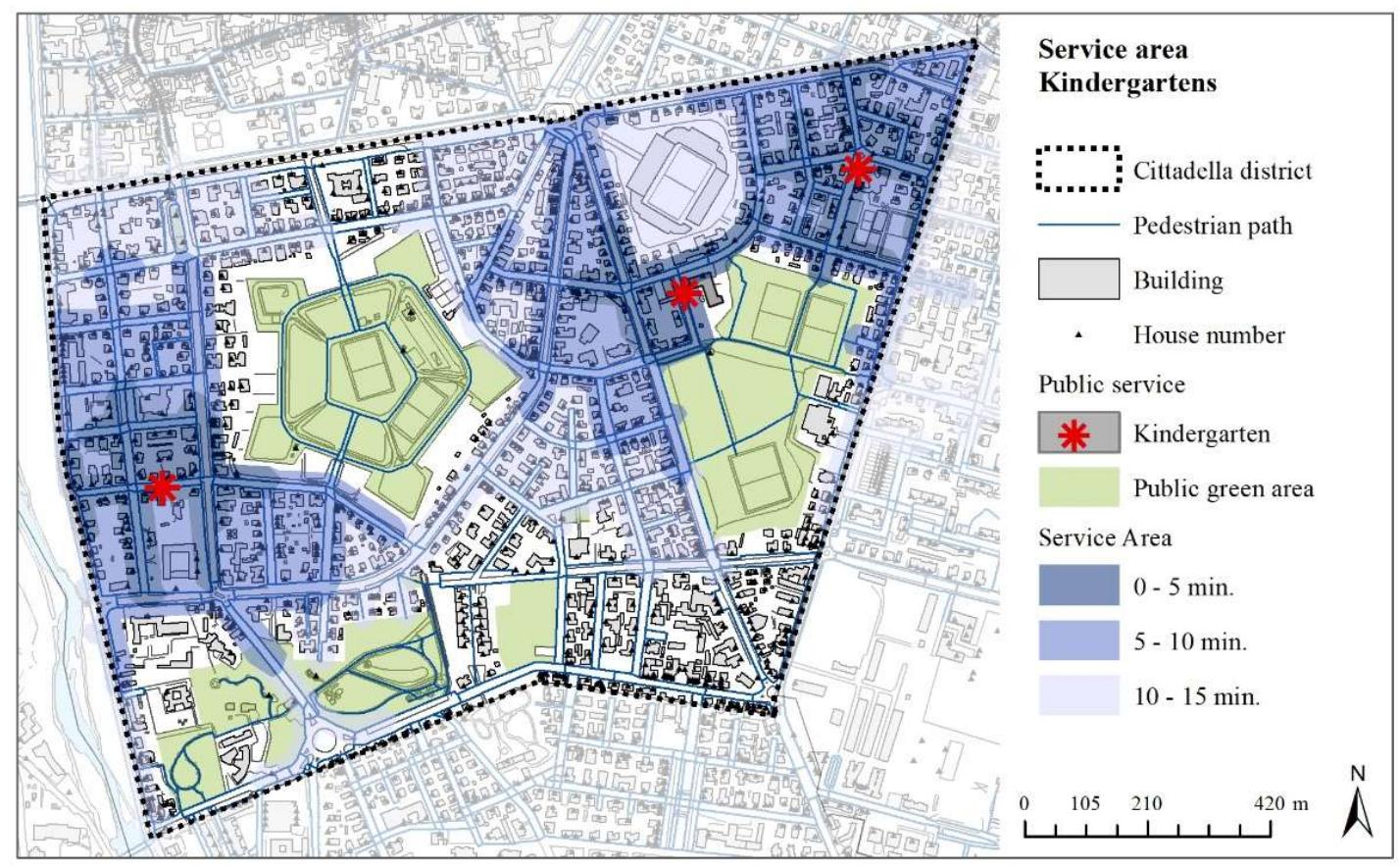

Figure 5: Service Area isochrone map concerning preschool facilities (kindergartens). Source: Authors.

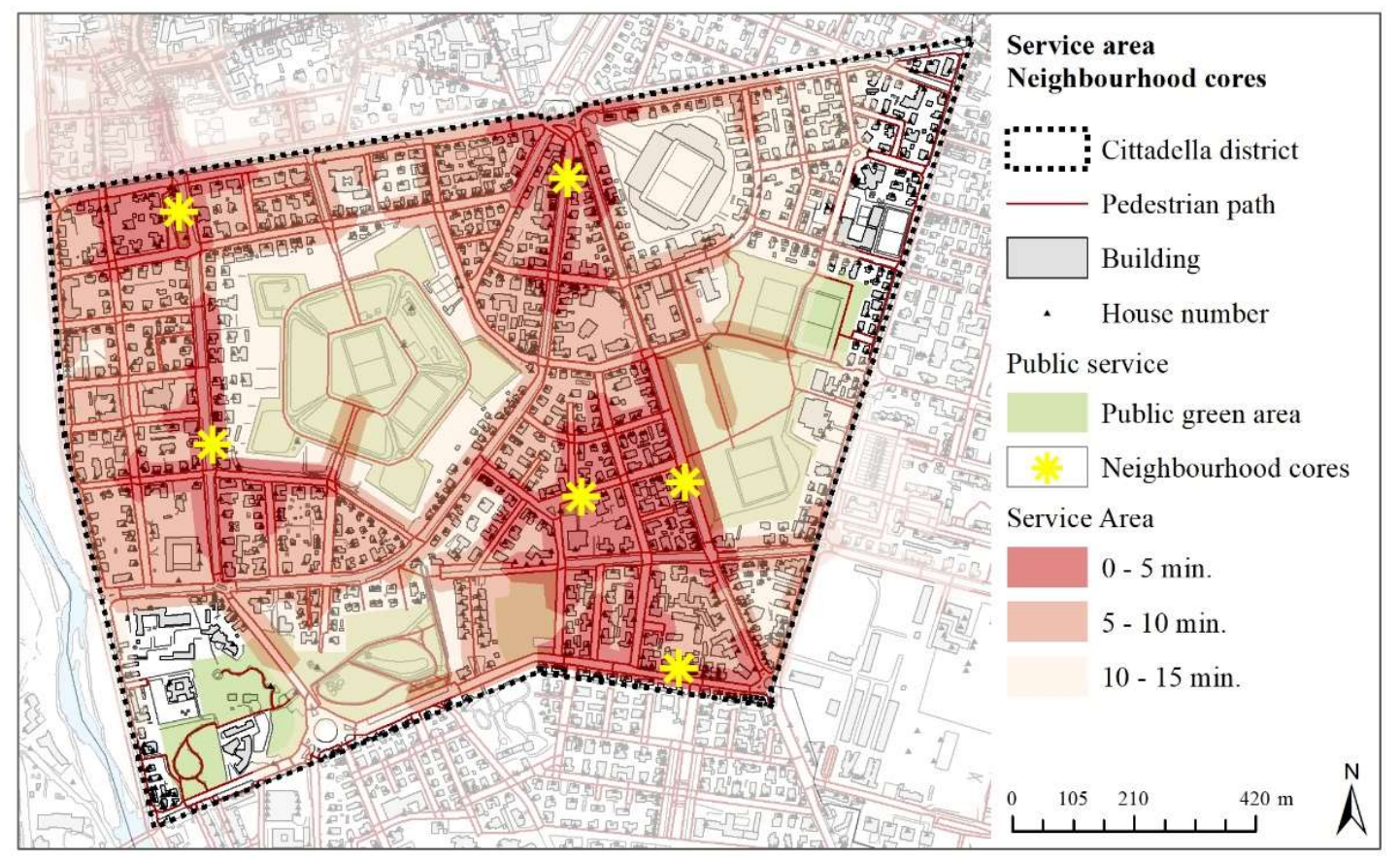

Figure 6: Service Area isochrone map concerning neighbourhood cores. Source: Authors. 


\subsection{Population distribution within the 5, 10 and 15-minute walking distance from the analysed facilities}

The following tables (Tab. 2 and 3) show the inhabitants distribution considering the distance from the analysed facilities located within the neighbourhood. Concerning kindergartens, it emerges that more than $70 \%$ of Cittadella's inhabitants have access to a kindergarten located in the same district within walking distance of 15 minutes.

Table 2: Inhabitants within walking distances from kindergartens

\begin{tabular}{lrrrrrrr}
\hline & Total & \multicolumn{2}{c}{$5 \min$} & \multicolumn{2}{c}{$10 \min$} & \multicolumn{2}{c}{$15 \min$} \\
\hline & $\mathrm{nr}$ & $\mathrm{nr}$ & $\%$ & $\mathrm{nr}$. & $\%$ & $\mathrm{nr}$. & $\%$ \\
Number of inhabitants & 10,692 & 1,509 & $14 \%$ & 4,830 & $45 \%$ & 7,553 & $71 \%$ \\
Number of kindergarten-aged & 352 & 48 & $14 \%$ & 184 & $52 \%$ & 261 & $74 \%$
\end{tabular}

inhabitants (3-6 years)

Source: Authors' elaboration on data from the municipal register database.

The percentage of inhabitants within walking distance from the neighbourhood cores with shops and facilities is even higher (up to $91 \%$ of the total), but of course there is a need to distinguish among the different types of shops and facilities to which access is needed.

Table 3: Inhabitants within walking distances from neighbourhood cores.

\begin{tabular}{rrrrrrrr}
\hline & Total & $5 \min$ & & $10 \min$ & \multicolumn{2}{c}{$15 \min$} \\
\hline \multirow{3}{*}{ Number of inhabitants } & $\mathrm{nr}$ & $\mathrm{nr}$ & $\%$ & $\mathrm{nr}$. & $\%$ & $\mathrm{nr}$ & $\%$ \\
& 10,692 & 3,678 & $34 \%$ & 8,111 & $76 \%$ & 9,736 & $91 \%$ \\
\hline
\end{tabular}

Source: Authors' elaboration on data from the municipal register database.

\section{Potentials and limits of the adopted model}

Within the framework of the 15-minute city, the paper proposes a methodology to assess the pedestrian accessibility at the neighbourhood level, starting from the creation of detailed isochrones of 5,10 and 15 minutes around basic neighbourhood services and facilities (in this paper, kindergartens and neighbourhood cores) and looking at the population distribution within the neighbourhood through a georeferencing process of its inhabitants.

Cities that, also looking at the post-pandemic emergencies, wants to return to more compact dimensions and to enhance proximity and walking, should encourage pedestrian mobility at the neighbourhood level, necessarily starting from understanding the daily needs of its inhabitants and ensuring them adequate conditions to easily and safely reach the various possible destinations they wish to engage with. The analytical model designed and developed using a Geographic Information System can support and facilitate the decision-making process by recognising and assessing the current walking accessibility levels within the neighbourhood and developing appropriate simulations designed to prefigure possible interventions on the public space.

However, some issues remain controversial in the monitoring of the 15-minute city. Firstly, the consideration of what should be the overall set of activities, services and equipment that constitute potential destinations capable of satisfying the pedestrian 
accessibility temporal objective. Secondly, which is the more appropriate temporal threshold for pedestrian accessibility to different services and facilities.

About the first issue, it seems unrealistic to provide a city with neighbourhoods hosting a complete endowment of all the hierarchical levels of equipment and services that can be used by general citizen. Therefore, it seems appropriate to question what should be prioritised in planning actions to implement the 15-minute city. This implies that, for comprehensive monitoring, the GIS model should consider a wider range of services and facilities, including amenities located in the surrounding neighbourhoods. The proposed methodology considers services and functions that satisfy citizen essential needs, as well as the daily or frequent access: local commerce (supermarkets, grocery stores, bars, drugstores), banks and preschool services. But it could also be enriched considering other primary school facilities, cultural and recreational facilities, equipped green areas, health and welfare facilities, sports facilities, public transport stops, and others (post office, administrative services). In this regard, however, a discussion could be opened on how plausible a definition of everyday use is today and on which and how many urban facilities and functions are accessible to everyday use in contemporary habits.

About the second issue, it seems fair to ask whether a 15-minute level of accessibility is suitable for all types of services. For example, in the case of kindergartens a lower time threshold (at 5 minutes) is certainly more appropriate, as proposed by Columbo's Organic urban planning. The 15-minute isochrone applied in the GIS model represents a benchmark value that, of course, can be re-assessed in the decision-making process, also looking at a widespread offer of services and facilities.

Finally, the outcomes of this analytical approach stress the dependence on a widespread localisation of neighbourhood services and facilities. Therefore, to plan neighbourhoods in a 15-minute perspective, the detailed functional organisation of the urban activities and a widespread location of services must fully intertwine with transport and slow mobility planning. Which possible interventions can be imagined for slow mobility infrastructures within the 5, 10 and 15-minute isochrones? Actions on road safety (comprising architectural barriers removal), security perception, and comfort all seem necessary, but this implies the necessity of a comprehensive analysis of the infrastructure quality. Concerning the GIS model presented, this implies a necessary implementation with a walkability assessment.

\section{Concluding remarks}

The analytical model, which can be further improved considering a wider range of services and facilities, can therefore represent a support tool in future public actions, especially in the operational processes of planning intervention priorities to enhance the pedestrian infrastructure and the facilities distribution. Ensuring the best possible accessibility conditions to public services and facilities becomes an essential aspect, based on a more complex process of encouraging walking towards a more resilient city capable of really rethinking itself 'beyond the car'.

The presented results lead to a conclusion that may appear somewhat obvious, but that seems appropriate to emphasise: the preparatory processes for the realisation of a 15minute city cannot elude the issues posed by the traditional planning of collective interest facilities and transport and soft mobility networks, and by a careful functional organisation of urban activities, comprising correct criteria for the localisation of services, seeking to attribute new vitality to the concept of urban neighbourhood unit. 
In this programmatic framework, the neighbourhood and proximity services categories can become the structures for reconstituting a network of centralities spread within the built continuum, albeit at different buildings and population densities (Zazzi, 2005). Processes aimed at decentralising urban life and services in neighbourhoods are generally not easy to achieve but, as also highlighted by the recent C40 cities guidelines (2021), constitute one of the privileged means to pursue a regeneration that ensures vital neighbourhoods, well connected, able to bring inhabitants back to where they live.

The survey approaches and design techniques for soft mobility infrastructures contributing to the pursuit of the 15-minute city objective also appear to be up to date within the national framework. They do not seem to require any innovation in the already available tools, relying on a consolidated knowledge that is widely available and acceptable for experimentation. It is more difficult to recognise in the approaches with which the 15-minute city project is approached the full awareness of the real complexity that characterises the population daily needs, conditioning their behaviour, modal choices, and the definition of systematic and non-systematic movements.

Therefore, the 'measurement' of the 15-minute city can certainly be achieved through traditional approaches, supported by territorial information systems based on the study of urban morphological and functional characteristics and socio-economic variables. However, for an effective understanding of the phenomena, these approaches must be integrated with direct observations of public spaces, surveys and investigations of pedestrian behaviour and mobility habits. Such surveys may also include the use of GPS devices for tracking real routes or the adoption of simulation models for building scenarios and behaviour-based mobility schemes.

However, the transition from the success of the 'slogan' to the persistence and rooting of its objectives and contents in the actual capacity for transforming cities does not only pass through the collection and cataloguing of even highly refined data. Increasingly, we must recognise that the success of the research outcomes has to do with the quality of knowledge dissemination. Consequently, the processes of knowledge transfer into the urban planning practice have to be assessed with appropriate instruments.

In conclusion, the renewed political and media attention to the idea of the 15-minute city has represented an opportunity for a broad collective reflection on the relevant, but not always considered, urban implications of mobility studies. In this sense, the reflection on the experimental approaches of mobility network redesign for the promotion of the 15-minute city, such as the Barcelona Supermanzana model, shows how sectorial interventions can nevertheless compete and be part of a coordinated management system to initiate an overall adaptation process of the city's urban spaces.

\section{References}

Balletto, G., Ladu, M., Milesi, A., Borruso, G. (2021) "A methodological approach on disused public properties in the 15-minute city perspective", Sustainability 13 (2), pp. 119.

Bertolini, L., le Clercq, F., Kapoen, L. (2005), "Sustainable accessibility: a conceptual framework to integrate transport and land use plan-making. Two test-applications in the Netherlands and a reflection on the way forward", Transport policy 12, pp. 207-220.

Bibri, S.E., Krogstie, J., Kärrholm, M. (2020) "Compact city planning and development: Emerging practices and strategies for achieving the goals of sustainability", Developments in the Built Environment 4, 100021. 
Busi, R. (2011), "Methods, Techniques and Policies for Mobility in the Friendly City", TeMA, Journal of Land Use, Mobility and Environment 4 (2), pp. 7-18

Calthorpe, P. (1993) The next American metropolis. Ecology, community, and the American dream, Princeton Architectural Press, New York.

Campisi, T., Ignaccolo, M., Inturri, G., Tesoriere, G., Torrisi, V. (2020), "Evaluation of walkability and mobility requirements of visually impaired people in urban spaces", Research in Transportation Business \& Management, 100592.

Carpentieri, G., Zucaro, F., Guida, C., Granata, L. (2019), “GIS-Based Spatial Analysis for the Integrated Transport-Land Use-Energy Planning: An Application to the Great London Area", Journal of Civil Engineering and Architecture 13, pp. 469-481.

Caselli, B., Rossetti, S., Ignaccolo, M., Zazzi, M., Torrisi, V. (2021), "Towards the Definition of a Comprehensive Walkability Index for Historical Centres", In: Gervasi, O. et al. (eds) Computational Science and Its Applications - ICCSA 2021, Lecture Notes in Computer Science, vol 12958, Springer, Cham.

Cervero, R., Kockelman, K. (1997), "Travel demand and the 3Ds: Density, diversity, and design", Transportation Research Part D: Transport and Environment 2 (3), pp. 199219.

Conticelli, E., Maimaris, A., Papageorgiou, G., Tondelli, S. (2018), "Planning and Designing Walkable Cities: A Smart Approach", In: Papa, R., Fistola, R., Gargiulo, C. (eds), Smart Planning: Sustainability and Mobility in the Age of Change, Green Energy and Technology, Springer, Cham.

Da Silva, D.C., King, D.A., Lemar, S. (2020), “Accessibility in practice: 20-minute city as a sustainability planning goal" Sustainability 12 (1), 129.

De Vos, J. (2020), "The effect of COVID-19 and subsequent social distancing on travel behavior", Transportation Research Interdisciplinary Perspectives 5.

FHWA (2008), Traffic Signal Timing Manual. United States Department of Transportation - Federal Highway Administration, Washingtion DC.

Garau, C., Annunziata, A., Yamu, C. (2020), “A walkability assessment tool coupling multi-criteria analysis and space syntax: The case study of Iglesias, Italy", European Planning Studies, pp. 1-23.

Gargiulo, C., Carpentieri, G., Gaglione, F., Guida, C., Sgambati, S., Zucaro, F. (2021), Le ageing cities tra passato e futuro. Strategie, metodi e proposte per migliorare l'accessibilità degli anziani ai servizi urbani, Federico II Open Access University Press, Napoli.

Handy, S., Clifton, K.J. (2001), "Evaluating neighbourhood accessibility. Possibilities and practicalities", Journal of transportation and statistic 4 (2), pp. 67-78.

Ignaccolo, M., Inturri, G., Giuffrida, N., Le Pira, M., Torrisi, V., Calabrò, G. (2020), "A step towards walkable environments: spatial analysis of pedestrian compatibility in an urban context", European Transport 76 (6), pp. 1-12.

Katz P. (1993), The New Urbanism: Toward an Architecture of Community, McGrawHill, New York.

Mezoued, A.M., Letesson, Q., Kaufmann, V. (2021), "Making the slow metropolis by designing walkability: a methodology for the evaluation of public space design and prioritizing pedestrian mobility", Urban Research \& Practice. 
Moreno, C., Allam, Z., Chabaud, D., Gall, C., Pratlong, F. (2021), "Introducing the '15Minute City': Sustainability, Resilience and Place Identity in Future Post-Pandemic Cities", Smart Cities 4 (1), pp. 93-111.

NACTO (2016), Global Street Design Guide, NACTO, New York.

National Research Council (2000), Highway Capacity Manual, TRB, Washington.

NCHRP (2015), Signal Timing Manual, The National Academies Press, Washington.

Perry, C.A. (1929), "The neighbourhood unit: A scheme of arrangement for the familylife community", In: Neighborhood and Community Planning, Regional Plan of New York and Its Environs, vol. 7, Committee on Regional Plan of New York and Its Environs, New York.

Pozoukidou, G., Chatziyiannaki, Z. (2021), “15-minute city: Decomposing the new urban planning eutopia”, Sustainability 13 (2), pp. 1-25.

Rossetti, S., Tiboni, M., Vetturi, D., Zazzi, M., Caselli, B. (2020), "Measuring pedestrian accessibility to public transport in urban areas: A GIS-based discretisation approach" European Transport $\backslash$ Trasporti Europei 76, 2.

Tiboni, M., Rossetti, S., Vetturi, D., Torrisi, V., Botticini, F., Schaefer, M.D. (2021), "Urban Policies and Planning Approaches for a Safer and Climate Friendlier Mobility in Cities: Strategies, Initiatives and Some Analysis", Sustainability 13 (4), 1778.

Tiboni, M., Ignaccolo, M. (eds.) (2020), Transport Infrastructure and systems in a changing world. Towards a more sustainable, reliable and smarter mobility. TIS Roma 2019 Conference Proceedings, Transportation Research Procedia 45, pp. 1-986.

Tira, M., Pezzagno, M., Richiedei, A. (eds.) (2020), Pedestrians, Urban Spaces and Health. Proceedings of the XXIV International Conference on Living and Walking in Cities (LWC 2019), CRC Press, London.

Urban Task Force (1999), Towards an Urban Renaissance, Spon, London.

Zazzi, M., Ventura, P., Caselli, B., Carra, M. (2018), "GIS-based monitoring and evaluation system as an urban planning tool to enhance the quality of pedestrian mobility in Parma", In: Pezzagno, M., Tira, M. (eds), Town and Infrastructure Planning for Safety and Urban Quality, CRC, Leiden, 87-94.

Zecca, C., Gaglione, F., Laing, R., Gargiulo, C. (2020), "Pedestrian routes and accessibility to urban services. Rhythmic analysis on people's behaviour before and during the Covid-19”, TeMA, Journal of Land Use, Mobility and Environment 13 (2), pp. 241-256.

Weng, M., Ding, N., Li, J., Jin, X., Xiao, H., He, Z., Su, S. (2019), “The 15-minute walkable neighbourhoods: Measurement, social inequalities and implications for building healthy communities in urban China", Journal of Transport \& Health 13, pp. 259-273.

\section{Acknowledgements}

The authors jointly designed and contributed to the paper. Conceptualization: M.Z., B.C., M.C., S.R.; Data curation: B.C., M.C., S.R.; Formal analysis: B.C., S.R.; methodology: B.C., M.C., S.R.; Supervision: M.Z.; Writing: B.C., M.C., S.R. All authors have read and agreed to the published version of the manuscript.

This research was partially funded by the University of Brescia, grant number" CUP: E81B19000840007 "and POR FESR Lombardia 2014-2020 (project: MoSoRe). 